\title{
Serum Albumin and Cerebro-cardiovascular Mortality During a 15-year Study in a Community-based Cohort in Tanushimaru, a Cohort of the Seven Countries Study
}

\author{
Yoko Umeki ${ }^{1}$, Hisashi Adachi ${ }^{2}$, Mika Enomoto ${ }^{3}$, Ako Fukami $^{3}$, Sachiko Nakamura ${ }^{3}$, \\ Yume Nohara ${ }^{3}$, Erika Nakao ${ }^{3}$, Akiko Sakaue $^{3}$, Tomoko Tsuru ${ }^{3}$, \\ Nagisa Morikawa ${ }^{3}$ and Yoshihiro Fukumoto ${ }^{3}$
}

\begin{abstract}
Objective There is little long-term data on the association between the serum albumin levels and mortality in community-based populations. We aimed to determine whether the serum albumin level is an independent risk factor for all-cause and cause-specific death in a community-based cohort study in Japan.

Methods In 1999, we performed a periodic epidemiological survey over a 15-year period in a population of 1,905 healthy subjects (783 males, 1,122 females) who were older than 40 years of age and who resided in Tanushimaru, a rural community, in Japan. Over the course of the study, we periodically examined the blood chemistry of the study subjects, including their serum albumin levels. Their baseline serum albumin levels were categorized into quartiles.

Results The baseline albumin levels were significantly associated with age (inversely), body mass index (BMI), diastolic blood pressure, lipid profiles [high density lipoprotein-cholesterol (HDL-c), low-density lipoprotein-cholesterol (LDL-c) and triglycerides] and estimated glomerular filtration rate (eGFR). After adjusting for confounders, a Cox proportional hazards regression analysis demonstrated that a low serum albumin level was an independent predictor of all-cause death [hazard ratio (HR): $0.39,95 \%$ confidence interval (CI): 0.24-0.65], cancer death (HR: 0.43, 95\% CI: 0.18-0.99), death from infection (HR: 0.21, 95\% CI: 0.060.73 ) and cerebro-cardiovascular death (HR: 0.19, 95\% CI: 0.06-0.63). The HRs for all-cause and cerebrocardiovascular death in the highest quartile vs. the lowest quartile of albumin after adjusting for confounders were 0.59 (95\%CI:0.39-0.88) and 0.15 (95\%CI: 0.03-0.66), respectively.
\end{abstract}

Conclusion The serum albumin level was thus found to be a predictor of all-cause and cerebrocardiovascular death in a general population.

Key words: albumin, mortality, epidemiology

(Intern Med 55: 2917-2925, 2016)

(DOI: 10.2169/internalmedicine.55.6931)

\section{Introduction}

Although it has been reported that low levels of serum albumin are associated with greater all-cause mortality in the general population $(1,2)$, the impact of serum albumin and nutrient intake on long-term mortality remains scant. The normal serum concentration of albumin in healthy adults is $\geq 4.0 \mathrm{~g} / \mathrm{dL}$, while hypoalbuminemia is defined as a serum albumin level of $\leq 3.4 \mathrm{~g} / \mathrm{L}$ (3). A meta-analysis by Vincent et al. (4) suggested that hypoalbuminemia is a powerful, reproducible and independent risk factor that predicts a poor outcome in patients with acute illness. This finding has been consistently and pervasively observed. In older veteran pa-

${ }^{1}$ Kurume University Graduate School of Medicine, Japan, ${ }^{2}$ Department of Community Medicine, Kurume University School of Medicine, Japan and ${ }^{3}$ Department of Internal Medicine, Division of Cardio-Vascular Medicine, Kurume University School of Medicine, Japan Received for publication December 3, 2015; Accepted for publication February 17, 2016 Correspondence to Dr. Hisashi Adachi, hadac@med.kurume-u.ac.jp 


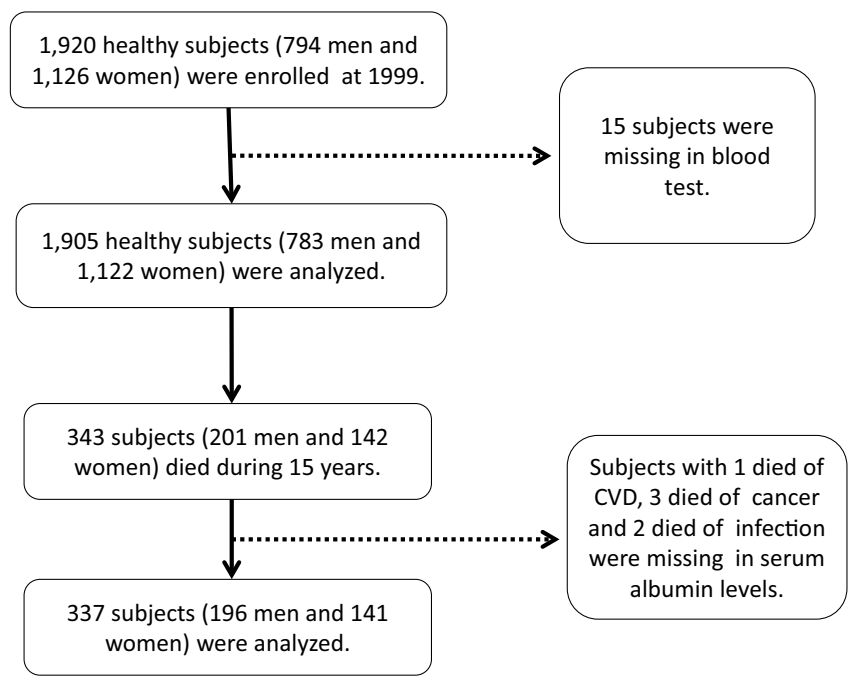

Figure 1. A flow diagram of the assessment of the study subjects.

tients, hypoalbuminemia at 3 months after hospital discharge was associated with a poor long-term prognosis (5). However, most reports have been limited to cause-specific death (6-9) and in-hospital outcomes $(10,11)$.

A study of patients with end-stage renal disease revealed that low serum albumin levels in the presence of vascular disease might not reflect the nutritional state (6). Hence, a reference standard of nutritional measurement should be used to determine the presence of protein malnutrition. Cooper et al. (7) also suggested that protein malnutrition and hypoalbuminemia are independent predictors of morbidity and mortality, whereas hypoalbuminemia predicts vascular morbidity (7), supporting the hypothesis that hypoalbuminemia is pathogenically associated with vascular disease, but the effect is dissociated from protein malnutrition in patients with end-stage renal disease.

To elucidate whether serum albumin levels and protein malnutrition are associated with cause-specific death and dietary habits, it is necessary to examine this relationship in a large number of subjects with confirmed dietary habits from a general population. We therefore investigated the relationships between serum albumin levels and protein malnutrition and cause-specific death in a general population in Japan.

\section{Materials and Methods}

\section{Subjects}

In 1999, we performed an epidemiological survey in Tanushimaru, a small rural community in southwestern Japan. This was a cohort of the Seven Countries Study (12). As previously reported, the demographic background of the subjects in this area is similar to that of the general Japanese population (13). Subjects with a known history of myocardial infarction $(n=2)$, stroke $(n=3)$, cancer $(n=5)$ or abnormal $\mathrm{Q}$ waves $(\mathrm{n}=5)$ (Minnesota codes I-1,2) (14) were excluded from the study. Finally, serum albumin data were obtained from 1,905 subjects (783 males, 1,122 females) of 40 to 95 years of age [40-49 years, $n=282$ (male, $n=102$; female, $n=$ 180 ); 50-59 years, $\mathrm{n}=450$ (male, $\mathrm{n}=178$; female, $\mathrm{n}=272$ ); 6069 years, $n=623$ (male, $n=259$; female, $n=364$ ); $70-79$ years, $\mathrm{n}=464$ (male, $\mathrm{n}=206$; female, $\mathrm{n}=258$ ); $\geq 80$ years, $\mathrm{n}=86$ (male, $\mathrm{n}=48$; female, $\mathrm{n}=38$ )], over a 15 -year period (Fig. 1). The respondents accounted for $48.2 \%$ of the men and $62.0 \%$ of the women in Tanushimaru who were older than 40 years of age (total target population: 3,463). The follow-up rate was $95.1 \%$.

\section{Data collection}

The subjects' medical history, alcohol intake, smoking habit, and current medications for hypertension, dyslipidemia, and diabetes were ascertained by questionnaire. The alcohol intake and smoking habit were classified according to whether or not the respondent was a current habitual user. The height and weight were measured, and the body mass index (BMI) was calculated as weight $(\mathrm{kg})$ divided by the square of height $\left(\mathrm{m}^{2}\right)$, as an index of obesity. Blood pressure (BP) was measured twice with the subject in the supine position. The second BP measurement was taken after 5 deep breaths and the 5th-phase diastolic pressure was used for the analysis. Blood was drawn from the antecubital vein for the determination of the fasting plasma glucose (FPG) and hemoglobin A1c level [HbA1c (NGSP)], the lipid profiles [total cholesterol, high density lipoprotein-cholesterol (HDL-c), low density lipoprotein-cholesterol (LDL-c) and triglycerides] and uric acid levels. The estimated glomerular filtration rate (eGFR) was calculated using the Modification of Diet in Renal Disease (MDRD) study equation modified with a Japanese coefficient: eGFR $\left(\mathrm{mL} \cdot \mathrm{min}^{-1} \cdot 1.73 \mathrm{~m}^{-2}\right)=194$ $\times$ age $^{-0.287} \times$ serum creatinine $e^{-1.094}($ if female $\times 0.739)(15)$. The serum albumin level was measured according to standard methods in a commercial laboratory (Kyodo Igaku Laboratory, Fukuoka, Japan).

\section{Nutritional data}

Dietary habits were evaluated by a food frequency questionnaire $(13,16)$. This questionnaire was modified for Japanese individuals by using an adaptation of atherosclerosis risk in communities (ARIC) study's food frequency questionnaire (17). It consisted of 105 items. Habitual nutrient intake was estimated based on reports of the average portion size of foods and the frequency at which they were consumed over the previous year. Due to the difference between Caucasian and Japanese diets, we added items and changed the portion size of the foods consumed. The following items were added according to the Japanese standard food composition tables (18); thick wheat flour noodles (udon), buchwheat noodles (soba), soybean paste (miso), soybean curd (tofu), fermented soybeans (natto), mushrooms, seaweed, and Japanese sweet. The following items were deleted due to the low frequency at which they were consumed, hamburger, hot dog, French fries, brown bread, peanut but- 
Table 1. Baseline Characteristics of the $\mathbf{1 , 9 0 5}$ Subjects Stratified by Serum Albumin Quartiles.

\begin{tabular}{|c|c|c|c|c|c|c|c|c|c|}
\hline \multirow[b]{2}{*}{ Characteristics } & \multicolumn{8}{|c|}{ Quartiles of albumin (g/dL) } & \multirow{2}{*}{$\mathrm{p}$ for trenc } \\
\hline & \multicolumn{2}{|c|}{ Q1 (Lowest) } & \multicolumn{2}{|r|}{ Q2 } & \multicolumn{2}{|c|}{ Q3 } & \multicolumn{2}{|c|}{ Q4 (Highest) } & \\
\hline Total, n & \multicolumn{2}{|c|}{476} & \multicolumn{2}{|c|}{476} & \multicolumn{2}{|c|}{476} & \multicolumn{2}{|c|}{477} & \\
\hline Albumin (g/dL) & 4.1 & 0.2 & 4.3 & 0.1 & 4.5 & 0.1 & 4.7 & 0.1 & $<0.0001$ \\
\hline Age (years) & 66.4 & \pm 11.2 & 63.6 & \pm 10.6 & 61.6 & \pm 10.8 & 59.1 & \pm 10.1 & $<0.0001$ \\
\hline Sex (\%males) & 213 & (44.7) & 186 & $(39.1)$ & 180 & (37.8) & 204 & (42.8) & 0.107 \\
\hline BMI $\left(\mathrm{kg} / \mathrm{m}^{2}\right)$ & 23.0 & \pm 3.4 & 23.0 & \pm 3.0 & 23.3 & \pm 3.0 & 23.1 & \pm 3.1 & 0.495 \\
\hline Systolic BP (mmHg) & 140.8 & \pm 21.7 & 139.0 & \pm 21.2 & 140.4 & \pm 22.7 & 140.2 & \pm 20.7 & 0.584 \\
\hline Diastolic BP (mmHg) & 81.2 & \pm 11.8 & 81.6 & \pm 12.2 & 82.2 & \pm 12.5 & 82.9 & \pm 12.0 & 0.144 \\
\hline Total cholesterol (mg/dL) & 187.9 & \pm 35.3 & 196.4 & \pm 32.7 & 203.0 & \pm 32.0 & 211.8 & \pm 34.0 & $<0.0001$ \\
\hline HDL-cholesterol (mg/dL) & 53.7 & \pm 12.6 & 55.9 & \pm 14.0 & 55.4 & \pm 13.2 & 58.2 & \pm 15.9 & $<0.0001$ \\
\hline LDL-cholesterol (mg/dL) & 114.4 & \pm 31.3 & 119.0 & \pm 30.8 & 123.9 & \pm 30.7 & 128.5 & \pm 34.1 & $<0.0001$ \\
\hline $\mathrm{TG}(\mathrm{mg} / \mathrm{dL}) *[$ range $]$ & 89 & [28-392] & 95 & [33-963] & 101 & [29-843] & 109 & {$[28-1,284]$} & $<0.0001$ \\
\hline eGFR $\left(\mathrm{mL} / \mathrm{mL}^{-1} / 1.73 \mathrm{~m}^{-2}\right)$ & 56.5 & \pm 13.4 & 57.1 & \pm 12.5 & 57.8 & \pm 12.7 & 58.9 & \pm 13.0 & 0.027 \\
\hline Uric acid $(\mathrm{mg} / \mathrm{dL})$ & 5.0 & \pm 1.5 & 4.9 & \pm 1.3 & 4.9 & \pm 1.3 & 5.1 & \pm 1.5 & 0.351 \\
\hline $\mathrm{HbA}_{1 \mathrm{c}}(\%)$ & 5.2 & \pm .8 & 5.2 & \pm .8 & 5.2 & \pm .6 & 5.2 & \pm .7 & 0.590 \\
\hline Alchol intake (\%yes) & 107 & $(22.5)$ & 100 & $(21.0)$ & 92 & (19.3) & 122 & (25.6) & 0.116 \\
\hline Current smoking (\%yes) & 87 & (18.3) & 78 & (16.4) & 69 & $(14.5)$ & 92 & (19.3) & 0.205 \\
\hline Medications & & & & & & & & & \\
\hline Hypertension (\%yes) & 101 & $(21.2)$ & 95 & $(20.0)$ & 87 & $(18.3)$ & 92 & $(19.3)$ & 0.716 \\
\hline Hyperlipidemia (\%yes) & 24 & $(5.0)$ & 23 & $(4.8)$ & 18 & $(3.8)$ & 26 & $(5.5)$ & 0.661 \\
\hline Diabetes (\%yes) & 19 & $(4.0)$ & 11 & $(2.3)$ & 17 & $(3.6)$ & 12 & $(2.5)$ & 0.377 \\
\hline
\end{tabular}

Data are means \pm standard deviations, geometric mean, range, or percent.

*Variables represented in the original scale after analysis using log (natural) transformed values.

BMI: body mass index, BP: blood pressure, eGFR: estimated glomerular filter, TG: triglycerides

ter, and low calorie carbonated water.

The frequency of intake and weights of the frequency were classified into the following 9 categories: 1$)$ once per day $(\times 1.0)$; 2$)$ two or three times per day $(\times 2.5)$; 3$)$ four to six times per day $(\times 5)$; 4) more than six times per day $(\times 7)$; $5)$ once per week $(x 0.14)$; 6$)$ two to four times per week ( $x$ $0.43)$; 7) five or six times per week $(\times 0.79) ; 8)$ one to three times per month $(\times 0.066)$; and 9$)$ never $(\times 0)(17)$.

The dietary data that were used for validation were compared with the results of the Japanese National Nutrition Survey in 1999 (19). The results of the National Nutrition Survey in 1999 are shown in parentheses. The total daily energy intake of the study subjects in the present study was $1,945 \mathrm{kcal}$ (vs. 1,988 kcal), the percentages of the daily calorie intake from carbohydrate, protein and fat were $58 \%$ (vs. 59\%), 19\% (vs. 16\%), and 23\% (vs. 24\%), respectively. Thus, the eating pattern in the subjects of the present study was similar to that reported in the results of the National Nutrition Survey.

We followed up the participants annually for 15 years (from 1999 to 2014). The causes of death were determined based on a review of obituaries, medical records, death certificates, hospital charts, and interviews with primary care physicians, the families of the deceased and other witnesses. The information was coded independently in accordance with the rules of the Seven Countries Study (12), and using the World Health Organization's 10th Revision of the International Statistical Classification of Diseases and Related Health Problems (WHO-ICD) (20). The follow-up data that were collected prior to the end of December 2014 were used in this study.

The present study was approved by the Ukiha and Tanushimaru Branches of the Japan Medical Association, the local citizens' committee of Tanushimaru, and by the Re- search Ethics Committee of the Kurume University School of Medicine (Process No. 9908/1999). The study conformed to the principles of the declaration of Helsinki. All of the participants provided written informed consent.

\section{Statistical analysis}

Natural logarithmic transformations were performed for the triglyceride values because of their skewed distribution. The triglyceride values after the analysis using log (natural)transformed values are presented in the original scale (Table 1,2$)$. In Tables 1 and 2 , the triglyceride values are presented as the geometric mean and range. Sex $(m e n=0$, women=1), smoking habits (non-smoker and former smoker $=0$, current smoker=1), alcohol intake (non-drinker and former drinker $=0$, current drinker $=1$ ), and medications for hypertension, dyslipidemia, and diabetes $(\mathrm{no}=0$, yes $=1$ ) were used as dummy variables. The mean serum albumin levels were classified into the following quartiles: $\leq 4.2 \mathrm{~g} / \mathrm{dL}, 4.2-$ $4.4 \mathrm{~g} / \mathrm{dL}, 4.4-4.6 \mathrm{~g} / \mathrm{dL}$, and $\geq 4.6 \mathrm{~g} / \mathrm{dL}$. The mean parameters, stratified by the albumin levels quartiles were compared using an analysis of variance. The survival curves for allcause death for each albumin quartile were estimated and compared using the Kaplan-Meier method and the log-rank statistic, respectively. For the categorical parameters, the $\chi^{2}$ test was used to test differences among groups. Uni- and multivariate regression analyses were performed using Cox's proportional hazards model to determine the factors associated with mortality from all causes, cancer, infection and cerebro-cardiovascular disease. In order to obtain hazard ratios (HRs) for all-cause, cancer, infection and cerebrocardiovascular disease death, stratified by the serum albumin level quartiles, we performed a Cox proportional hazards regression analysis after adjusting for confounding factors. $p$ values of $<0.05$ were considered to indicate statistical sig- 
Table 2. Baseline Means of Nutrient Intake Stratified by Albumin Quartiles.

\begin{tabular}{|c|c|c|c|c|c|c|c|c|c|c|}
\hline \multirow[b]{2}{*}{ Characteristics } & \multicolumn{9}{|c|}{ Quartiles of albumin (g/dL) } & \multirow{2}{*}{$\mathrm{p}$ for trend } \\
\hline & \multicolumn{3}{|c|}{ Q1 (Lowest) } & \multicolumn{2}{|r|}{ Q2 } & \multicolumn{2}{|c|}{$\mathrm{Q} 3$} & \multicolumn{2}{|c|}{ Q4 (Highest) } & \\
\hline Total, $\mathrm{n}$ & \multicolumn{3}{|c|}{476} & \multicolumn{2}{|r|}{476} & \multicolumn{2}{|c|}{476} & \multicolumn{2}{|c|}{477} & \\
\hline Albumin (g/dL) & 4.1 & \pm & 0.2 & 4.3 & 0.1 & 4.5 & 0.1 & 4.7 & 0.1 & $<0.0001$ \\
\hline Energy $(\mathrm{kcal} /$ day $) *[$ range] & 1,858 & & $817-4,339]$ & 1,882 & {$[869-4,962]$} & 1,850 & {$[913-4,097]$} & 1,897 & {$[849-4,443]$} & 0.486 \\
\hline Total protein (g/day) & 91.3 & \pm & 33.6 & 92.4 & \pm 32.6 & 92.0 & \pm 32.1 & 93.1 & \pm 35.3 & 0.870 \\
\hline Animal protein (g/day) & 38.7 & \pm & 18.1 & 40.2 & \pm 18.6 & 38.8 & \pm 18.7 & 39.2 & \pm 19.5 & 0.586 \\
\hline Vegetable protein (g/day) & 52.6 & \pm & 23.4 & 52.2 & \pm 22.0 & 53.2 & \pm 22.6 & 53.9 & \pm 24.0 & 0.693 \\
\hline Total fat (g/day) & 49.1 & \pm & 19.3 & 51.2 & \pm 20.1 & 50.5 & \pm 19.9 & 50.5 & \pm 21.7 & 0.425 \\
\hline Animal fat (g/day) & 22.9 & \pm & 12.9 & 24.2 & \pm 13.3 & 23.2 & \pm 13.3 & 23.7 & \pm 13.9 & 0.394 \\
\hline Vegetable fat (g/day) & 26.3 & \pm & 10.1 & 27.0 & \pm 10.5 & 27.3 & \pm 10.7 & 26.8 & \pm 11.2 & 0.462 \\
\hline Carbohydrate (g/day) & 333.9 & \pm & 103.4 & 331.1 & \pm 106.9 & 331.0 & \pm 100.2 & 340.3 & \pm 110.0 & 0.484 \\
\hline Saturate fat (g/day) & 11.1 & \pm & 4.8 & 11.6 & \pm 5.0 & 11.5 & \pm 5.0 & 11.6 & \pm 5.4 & 0.449 \\
\hline Monounsaturated fat (g/day) & 14.5 & \pm & 6.3 & 15.1 & \pm 6.6 & 14.9 & \pm 6.4 & 14.9 & \pm 6.9 & 0.557 \\
\hline Polyunsaturated fat (g/day) & 10.7 & \pm & 4.0 & 11.0 & \pm 4.4 & 11.1 & \pm 4.0 & 10.8 & \pm 4.5 & 0.450 \\
\hline Linoleic acid (mg/day) & $8,144.0$ & \pm & $3,128.2$ & $8,474.7$ & $\pm 3,509.5$ & $8,461.6$ & $\pm 3,180.8$ & $8,261.4$ & $\pm 3,445.7$ & 0.345 \\
\hline Arachidonic acid (mg/day) & 126.5 & \pm & 56.0 & 127.3 & \pm 58.0 & 122.8 & \pm 56.3 & 125.3 & \pm 58.1 & 0.650 \\
\hline \multicolumn{11}{|l|}{ N-3 fatty acid (mg/day) } \\
\hline Linolenic acid (mg/day) & $1,281.4$ & \pm & 615.1 & $1,336.0$ & \pm 685.4 & $1,319.6$ & \pm 624.5 & $1,278.9$ & \pm 652.0 & 0.434 \\
\hline EPA (mg/day) & 311.7 & \pm & 192.0 & 306.6 & \pm 182.2 & 322.3 & \pm 247.3 & 330.8 & \pm 223.0 & 0.299 \\
\hline DHA (mg/day) & 493.6 & \pm & 281.7 & 486.1 & \pm 266.8 & 507.5 & \pm 361.8 & 518.2 & \pm 318.7 & 0.387 \\
\hline
\end{tabular}

Data are means \pm standard deviations, geometric mean, range, or percent.

*Variables represented in the original scale after analysis using log (natural) transformed values.

EPA: Eicosapentaenoic acid, DHA: Docosahexaenoic acid

nificance. All of the statistical analyses were performed using the SAS software program (version 9.3, SAS Institute, Cary, USA).

\section{Results}

There were 343 deaths (male, $n=201$; female, $n=142$ ). The causes of death were as follows: cancer, $\mathrm{n}=102$ $(29.7 \%)$; cerebro-cardiovascular disease, $\mathrm{n}=48$ (14.0\%); infection, $n=45$ (13.1\%); other causes, $n=69$ (20.1\%); and unknown, $\mathrm{n}=79$ (23.0\%). The 102 cancer deaths included, malignancies of the digestive system $(n=34)$, liver, bile duct and pancreas $(n=29)$, malignancies of the respiratory system $(n=19)$, hematological malignancies $(n=10)$, and other types of malignancy $(n=10)$. The serum albumin levels were missing from the reports of 1 subject who died of cerebrocardiovascular disease, 3 who died of cancer, and 2 who died of infection. Eventually, the data of 337 subjects (male, $\mathrm{n}=196$; female, $\mathrm{n}=141$ ) were analyzed (Fig. 1).

Table 1 shows the baseline characteristics of the 1,905 subjects stratified by the serum albumin quartiles. The baseline characteristics of age $(\mathrm{p}<0.001$; inversely), total cholesterol $(\mathrm{p}<0.001)$, HDL-c $(\mathrm{p}<0.001)$, LDL-c $(\mathrm{p}<0.001)$, logtransformed triglycerides $(\mathrm{p}<0.001)$ and eGFR $(\mathrm{p}<0.05)$ were significantly associated with the albumin quartiles. Table 2 shows the baseline nutrient characteristics of the 1,905 subjects stratified by the serum albumin quartiles. The baseline nutrient intake levels were not significantly associated with the serum albumin quartiles.

Three hundred forty-three of the 1,905 subjects died (male, $\mathrm{n}=201$; female, $\mathrm{n}=142$ ) during the 15-year follow-up period. In a Cox proportional hazards model with all-cause and cause-specific death as the outcome variable, a low albumin level was found to be a predictor of all-cause death [HR, 0.39; 95\% confidence interval (CI), 0.24-0.65; $\mathrm{p}<$ $0.001]$, cancer death (HR, 0.43; 95\% CI, 0.18-0.99; $\mathrm{p}=$ 0.049), death from infection (HR, 0.21; 95\% CI, 0.06-0.73; $\mathrm{p}=0.014)$ and cerebro-cardiovascular disease-related death (HR, 0.19; 95\% CI, 0.06-0.63; p=0.006) (Table 3). In a Cox proportional hazards model with all-cause and cause-specific death as the outcome variable, with the exception of vegetable protein (for cancer death), none of the baseline nutrient levels was significantly associated with the outcome (Table 4).

We categorized the baseline albumin levels into quartiles and calculated the HRs for all-cause, cancer, infection and cerebro-cardiovascular disease death using the lowest quartile as the reference value (Table 5). The HRs for all-cause and cerebro-cardiovascular disease death in the lowest quartile vs. the highest serum albumin quartile (after adjusting for age, sex, HDL-c, LDL-c, triglycerides and eGFR) were 0.59 (95\%CI: $0.39-0.88$ ) and 0.15 (95\%CI: $0.03-0.66)$, respectively.

In the Kaplan-Meier curves for the cumulative survival rate, stratified by the serum albumin quartiles, the lowest quartile group showed the worst all-cause mortality in a significant albumin level-dependent manner (log rank statistic= 22.9; $\mathrm{p}<0.0001$ ) among the four groups (Fig. 2).

\section{Discussion}

The novel findings of the present study were that the se- 
Table 3. Cox Proportional Hazards Model with All-cause and Cause-specific Deaths as the Outcome Variables.

\begin{tabular}{|c|c|c|c|c|c|c|c|c|}
\hline \multicolumn{9}{|l|}{ All-cause deaths $(n=337)$} \\
\hline \multirow{2}{*}{$\frac{\text { parameter }}{\text { Albumin }(\mathrm{g} / \mathrm{dL})}$} & \multirow{2}{*}{$\frac{\beta}{-0.931}$} & \multirow{2}{*}{$\frac{\mathrm{SE}}{0.256}$} & \multicolumn{4}{|c|}{$\mathrm{HR}(95 \% \mathrm{CI})$} & & \multirow{2}{*}{$\begin{array}{l}\mathrm{p} \text { value } \\
<0.0001\end{array}$} \\
\hline & & & 0.39 & 0.24 & - & 0.65 & ) & \\
\hline Age (years) & 0.099 & 0.007 & 1.10 & 1.09 & - & 1.12 & ) & $<0.0001$ \\
\hline Total cholesterol (mg/dL) & -0.004 & 0.010 & 1.00 & 0.98 & - & 1.02 & ) & 0.718 \\
\hline HDL-cholesterol (mg/dL) & 0.007 & 0.012 & 1.01 & 0.98 & - & 1.03 & ) & 0.544 \\
\hline LDL-cholesterol(mg/dL) & -0.006 & 0.010 & 0.99 & 0.98 & - & 1.01 & ) & 0.557 \\
\hline Triglycerides $(\mathrm{mg} / \mathrm{dL})^{*}$ & 0.218 & 0.319 & 1.24 & 0.67 & - & 2.32 & ) & 0.493 \\
\hline eGFR $\left(\mathrm{mL} / \mathrm{mL}^{-1} / 1.73 \mathrm{~m}^{-2}\right)$ & -0.004 & 0.005 & 1.00 & 0.99 & - & 1.01 & ) & 0.463 \\
\hline
\end{tabular}

\begin{tabular}{|c|c|c|c|c|c|c|c|c|}
\hline \multirow{2}{*}{$\frac{\text { parameter }}{\text { Albumin }(\mathrm{g} / \mathrm{dL})}$} & \multirow{2}{*}{$\frac{\beta}{-0.855}$} & \multirow{2}{*}{$\frac{\mathrm{SE}}{0.435}$} & \multicolumn{4}{|c|}{$\mathrm{HR}(95 \% \mathrm{CI})$} & & \multirow{2}{*}{$\frac{\mathrm{p} \text { value }}{0.049}$} \\
\hline & & & 0.43 & 0.18 & - & 0.99 & ) & \\
\hline Age (years) & 0.078 & 0.012 & 1.08 & 1.06 & - & 1.11 & ) & $<0.0001$ \\
\hline Total cholesterol (mg/dL) & -0.059 & 0.036 & 0.94 & 0.88 & - & 1.01 & ) & 0.105 \\
\hline HDL-cholesterol (mg/dL) & 0.049 & 0.038 & 1.05 & 0.98 & - & 1.13 & ) & 0.198 \\
\hline LDL-cholesterol (mg/dL) & 0.048 & 0.036 & 1.05 & 0.98 & - & 1.13 & ) & 0.184 \\
\hline Triglycerides $(\mathrm{mg} / \mathrm{dL})^{*}$ & 1.512 & 0.891 & 4.54 & 0.79 & - & 26.03 & ) & 0.090 \\
\hline eGFR $\left(\mathrm{mL} / \mathrm{mL}^{-1} / 1.73 \mathrm{~m}^{-2}\right)$ & 0.015 & 0.009 & 1.02 & 1.01 & - & 1.03 & ) & 0.084 \\
\hline
\end{tabular}

\begin{tabular}{|c|c|c|c|c|c|c|c|c|}
\hline \multirow{2}{*}{$\frac{\text { parameter }}{\text { Albumin }(\mathrm{g} / \mathrm{dL})}$} & \multirow{2}{*}{$\frac{\beta}{-1.584}$} & \multirow{2}{*}{$\frac{\mathrm{SE}}{0.644}$} & \multicolumn{4}{|c|}{$\mathrm{HR}(95 \% \mathrm{CI})$} & & \multirow{2}{*}{$\frac{\mathrm{p} \text { value }}{0.014}$} \\
\hline & & & 0.21 & 0.06 & - & 0.73 & ) & \\
\hline Age (years) & 0.133 & 0.018 & 1.14 & 1.1 & - & 1.19 & ) & $<0.0001$ \\
\hline Total cholesterol (mg/dL) & 0.001 & 0.033 & 1.00 & 0.94 & - & 1.07 & ) & 0.973 \\
\hline HDL-cholesterol (mg/dL) & 0.017 & 0.035 & 1.02 & 0.95 & - & 1.09 & ) & 0.628 \\
\hline LDL-cholesterol (mg/dL) & -0.009 & 0.032 & 0.99 & 0.93 & - & 1.05 & ) & 0.771 \\
\hline Triglycerides $(\mathrm{mg} / \mathrm{dL})^{*}$ & 0.077 & 0.888 & 1.08 & 0.19 & - & 6.15 & ) & 0.931 \\
\hline $\mathrm{eGFR}\left(\mathrm{mL} / \mathrm{mL}^{-1} / 1.73 \mathrm{~m}^{-2}\right)$ & 0.009 & 0.013 & 1.01 & 0.98 & - & 1.04 & ) & 0.503 \\
\hline
\end{tabular}

\begin{tabular}{|c|c|c|c|c|c|c|c|c|}
\hline \multirow{2}{*}{$\frac{\text { parameter }}{\text { Albumin }(\mathrm{g} / \mathrm{dL})}$} & \multirow{2}{*}{$\frac{\beta}{-1.643}$} & \multirow{2}{*}{$\frac{\mathrm{SE}}{0.599}$} & \multicolumn{4}{|c|}{$\mathrm{HR}(95 \% \mathrm{CI})$} & & \multirow{2}{*}{$\frac{\mathrm{p} \text { value }}{0.006}$} \\
\hline & & & 0.19 & 0.06 & - & 0.63 & ) & \\
\hline Age (years) & 0.091 & 0.016 & 1.10 & 1.06 & - & 1.13 & ) & $<0.0001$ \\
\hline Total cholesterol (mg/dL) & 0.014 & 0.017 & 1.01 & 0.98 & - & 1.05 & ) & 0.412 \\
\hline HDL-cholesterol (mg/dL) & -0.002 & 0.021 & 1.00 & 0.96 & - & 1.04 & ) & 0.943 \\
\hline LDL-cholesterol (mg/dL) & -0.022 & 0.016 & 0.98 & 0.95 & - & 1.01 & ) & 0.162 \\
\hline Triglycerides $(\mathrm{mg} / \mathrm{dL})^{*}$ & -0.330 & 0.623 & 0.72 & 0.21 & - & 2.44 & ) & 0.597 \\
\hline $\mathrm{eGFR}\left(\mathrm{mL} / \mathrm{mL}^{-1} / 1.73 \mathrm{~m}^{-2}\right)$ & -0.016 & 0.012 & 0.98 & 0.96 & - & 1.01 & ) & 0.984 \\
\hline
\end{tabular}

CVD: Cerebro-cardiovascular diseases, CI: confidence interval, HR: hazard ratio,

eGFR: estimated glomerular filter

rum albumin level was a predictor of all-cause and cerebrocardiovascular disease death, even in healthy individuals, during a 15-year follow-up period, and that the serum albumin level was not correlated with nutrition intake. Although two previous reports $(1,2)$ from Japanese investigators demonstrated a strong association between the serum albumin level and all-cause death in a community-based population, the present study reported that the serum albumin level was associated with both all-cause and cerebro-cardiovascular disease death.

To determine the causes of death, we used a review of obituaries, medical records, death certificates, hospital charts, and interviews with primary care physicians, family members of the deceased and other witnesses. The information was carefully independently coded in accordance with the rules of the Seven Countries Study (12).

Among the participants of the present study (mean albumin level; $4.4 \mathrm{~g} / \mathrm{dL})$, only 89 subjects $(4.7 \%)$ showed an al- bumin level of $\leq 4.0 \mathrm{~g} / \mathrm{dL}$. Based on the findings of this study, we hypothesize that nutritional deficiencies (low albumin and low cholesterol) may be important in the pathology of all-cause and cause-specific death. It is interesting to note that hypoalbuminemia has been associated with hemorrhagic stroke in previous studies $(21,22)$, and that hypoalbuminemia has been associated with cause-specific death and diseases in many studies including our own study (23-31). It has been demonstrated that low albumin levels are associated with long-term protein-energy deprivation, liver disease (30) and renal disease $(6,7,25)$, acute illness $(4,9-11$, $26,29)$ and chronic illness $(8,25)$, inflammation (31) and poor physical function (24). There is increasing evidence to show that low albumin levels are associated with cancer (27). However, whether low levels of albumin are associated with the nutritional status and disease of healthy participants has not previously been elucidated. Four subjects died within 1 year of enrollment due to hepatocyte cell car- 
Table 4. Cox Proportional Hazards Model with All-cause and Cause-specific Deaths as the Nutrient Intakes.

\begin{tabular}{|c|c|c|c|c|c|c|c|}
\hline \multicolumn{8}{|l|}{ All-cause deaths $(n=337)$} \\
\hline \multirow{2}{*}{$\begin{array}{l}\text { Vaiables } \\
\text { Sex (men=0,women=1) }\end{array}$} & \multirow{2}{*}{$\frac{\beta}{-0.837}$} & \multirow{2}{*}{$\begin{array}{l}\mathrm{SE} \\
0.140\end{array}$} & \multicolumn{4}{|c|}{$\mathrm{HR}(95 \% \mathrm{CI})$} & \multirow{2}{*}{$\frac{\mathrm{p} \text { value }}{<0.0001}$} \\
\hline & & & 0.433 & $(0.329$ & - & $0.569)$ & \\
\hline Age (years) & 0.116 & 0.007 & 1.123 & 1.108 & - & $1.139)$ & $<0.0001$ \\
\hline Energy (kcal/day) & 0.000 & 0.000 & 1.000 & 0.999 & - & $1.000)$ & 0.402 \\
\hline Animal protein (g/day) & -0.009 & 0.011 & 0.991 & 0.971 & - & $1.012)$ & 0.422 \\
\hline Vegetable protein (g/day) & 0.016 & 0.009 & 1.016 & 0.999 & - & $1.034)$ & 0.066 \\
\hline Animal protein/vegetable protein & 0.481 & 0.342 & 1.617 & 0.828 & - & $3.159)$ & 0.159 \\
\hline Animal fat (g/day) & -0.005 & 0.013 & 0.995 & 0.969 & - & $1.021)$ & 0.699 \\
\hline Vegetable fat (g/day) & 0.020 & 0.013 & 1.020 & 0.994 & - & $1.047)$ & 0.135 \\
\hline Animal fat/vegetable fat & 0.273 & 0.253 & 1.314 & 0.800 & - & $2.158)$ & 0.282 \\
\hline Carbohydrate (g/day) & -0.001 & 0.002 & 0.999 & 0.995 & - & $1.004)$ & 0.723 \\
\hline EPA (mg/day) & -0.001 & 0.002 & 0.999 & 0.995 & - & $1.002)$ & 0.451 \\
\hline DHA (mg/day) & 0.001 & 0.001 & 1.001 & $(0.998$ & - & $1.003)$ & 0.587 \\
\hline \multicolumn{8}{|l|}{ Cancer deaths $(n=99)$} \\
\hline Vaiables & $\beta$ & SE & & $\operatorname{HR}(95 \%$ & & & $\mathrm{p}$ value \\
\hline $\operatorname{Sex}(\operatorname{men}=0$, women $=1)$ & -0.571 & 0.234 & 0.565 & $(0.357$ & - & $0.894 \quad)$ & 0.015 \\
\hline Age (years) & 0.099 & 0.011 & 1.104 & 1.080 & - & $1.128)$ & $<0.0001$ \\
\hline Energy (kcal/day) & 0.000 & 0.001 & 1.000 & 0.999 & - & $1.002)$ & 0.644 \\
\hline Animal protein (g/day) & -0.018 & 0.017 & 0.982 & 0.949 & - & $1.016)$ & 0.295 \\
\hline Vegetable protein (g/day) & 0.028 & 0.014 & 1.028 & 1.001 & - & $1.056)$ & 0.045 \\
\hline Animal protein/vegetable protein & 0.324 & 0.605 & 1.382 & 0.422 & - & $4.526)$ & 0.593 \\
\hline Animal fat (g/day) & -0.006 & 0.022 & 0.994 & 0.953 & - & 1.037 ) & 0.778 \\
\hline Vegetable fat (g/day) & 0.009 & 0.021 & 1.009 & 0.968 & - & $1.051)$ & 0.680 \\
\hline Animal fat/vegetable fat & 0.374 & 0.415 & 1.453 & 0.644 & - & $3.280)$ & 0.368 \\
\hline Carbohydrate (g/day) & -0.004 & 0.004 & 0.996 & 0.989 & - & $1.004)$ & 0.330 \\
\hline EPA (mg/day) & -0.001 & 0.002 & 0.999 & 0.996 & - & $1.003)$ & 0.743 \\
\hline DHA (mg/day) & 0.001 & 0.001 & 1.001 & $(0.998$ & - & $1.004)$ & 0.517 \\
\hline \multicolumn{8}{|l|}{ Infection deaths $(\mathrm{n}=43)$} \\
\hline Vaiables & $\beta$ & SE & & $\operatorname{HR}(95 \%$ & & & $\mathrm{p}$ value \\
\hline $\operatorname{Sex}(\operatorname{men}=0$, women $=1)$ & -1.591 & 0.396 & 0.204 & 0.094 & - & $0.442)$ & 0.000 \\
\hline Age (years) & 0.142 & 0.020 & 1.153 & 1.109 & - & $1.198)$ & $<0.0001$ \\
\hline Energy (kcal/day) & -0.001 & 0.001 & 0.999 & 0.997 & - & $1.001)$ & 0.465 \\
\hline Animal protein (g/day) & -0.013 & 0.032 & 0.987 & 0.926 & - & $1.052)$ & 0.692 \\
\hline Vegetable protein (g/day) & -0.006 & 0.027 & 0.994 & 0.943 & - & $1.048)$ & 0.831 \\
\hline Animal protein/vegetable protein & 0.193 & 1.060 & 1.213 & 0.152 & - & $9.684)$ & 0.855 \\
\hline Animal fat (g/day) & 0.042 & 0.040 & 1.043 & 0.964 & - & $1.128)$ & 0.299 \\
\hline Vegetable fat (g/day) & 0.013 & 0.040 & 1.014 & 0.937 & - & $1.097)$ & 0.739 \\
\hline Animal fat/vegetable fat & -0.608 & 0.842 & 0.544 & 0.105 & - & $2.834)$ & 0.470 \\
\hline Carbohydrate (g/day) & 0.001 & 0.007 & 1.001 & 0.989 & - & $1.015)$ & 0.820 \\
\hline EPA (mg/day) & -0.009 & 0.005 & 0.991 & 0.981 & - & $1.001)$ & 0.068 \\
\hline DHA (mg/day) & 0.006 & 0.003 & 1.006 & $(0.999$ & - & $1.013)$ & 0.080 \\
\hline \multicolumn{8}{|l|}{ CVD deaths $(n=47)$} \\
\hline Vaiables & $\beta$ & SE & & $\operatorname{HR}(95 \%$ & & & $\mathrm{p}$ value \\
\hline $\operatorname{Sex}($ men= $=0$, women $=1)$ & -0.780 & 0.342 & 0.458 & $(0.234$ & - & 0.896 ) & 0.023 \\
\hline Age (years) & 0.118 & 0.017 & 1.126 & 1.088 & - & $1.164)$ & $<0.0001$ \\
\hline Energy (kcal/day) & -0.001 & 0.001 & 0.999 & 0.997 & - & $1.001)$ & 0.314 \\
\hline Animal protein (g/day) & 0.032 & 0.024 & 1.032 & 0.984 & - & $1.082)$ & 0.193 \\
\hline Vegetable protein (g/day) & 0.002 & 0.023 & 1.002 & 0.958 & - & $1.048)$ & 0.933 \\
\hline Animal protein/vegetable protein & 0.202 & 0.799 & 1.224 & 0.256 & - & $5.855)$ & 0.801 \\
\hline Animal fat (g/day) & -0.013 & 0.032 & 0.987 & 0.928 & - & $1.051)$ & 0.692 \\
\hline Vegetable fat (g/day) & 0.036 & 0.034 & 1.037 & 0.970 & - & $1.108)$ & 0.288 \\
\hline Animal fat/vegetable fat & 0.176 & 0.653 & 1.192 & 0.331 & - & $4.289)$ & 0.788 \\
\hline Carbohydrate (g/day) & 0.003 & 0.006 & 1.003 & 0.991 & - & $1.016)$ & 0.581 \\
\hline EPA (mg/day) & -0.002 & 0.005 & 0.998 & 0.989 & - & $1.008)$ & 0.751 \\
\hline DHA (mg/day) & -0.001 & 0.003 & 0.999 & 0.992 & - & $1.005)$ & 0.700 \\
\hline
\end{tabular}

EPA: Eicosapentaenoic acid, DHA: Docosahexaenoic acid

cinoma (3.6 months), subarachnoid hemorrhage (4.8 months), lung cancer (6 months), and an accident (7.2 months). The low albumin levels in the 2 subjects who died of cancer might have affected the results; however, we were not able to exclude the cases, because their records did not describe any history of cancer treatment nor was there any information to suggest that they were undergoing cancer treatment at the start of the study period.

Hypoalbuminemia, which can be associated with various diseases, is frequently observed in hospitalized patients (24-31). Regardless of the cause, hypoalbuminemia has a strong impact on mortality and morbidity. However, in 
Table 5. Hazard Ratios of All-cause, Cancer, Infection and CVD Mortality Using the Lowest Quartile as the Reference.

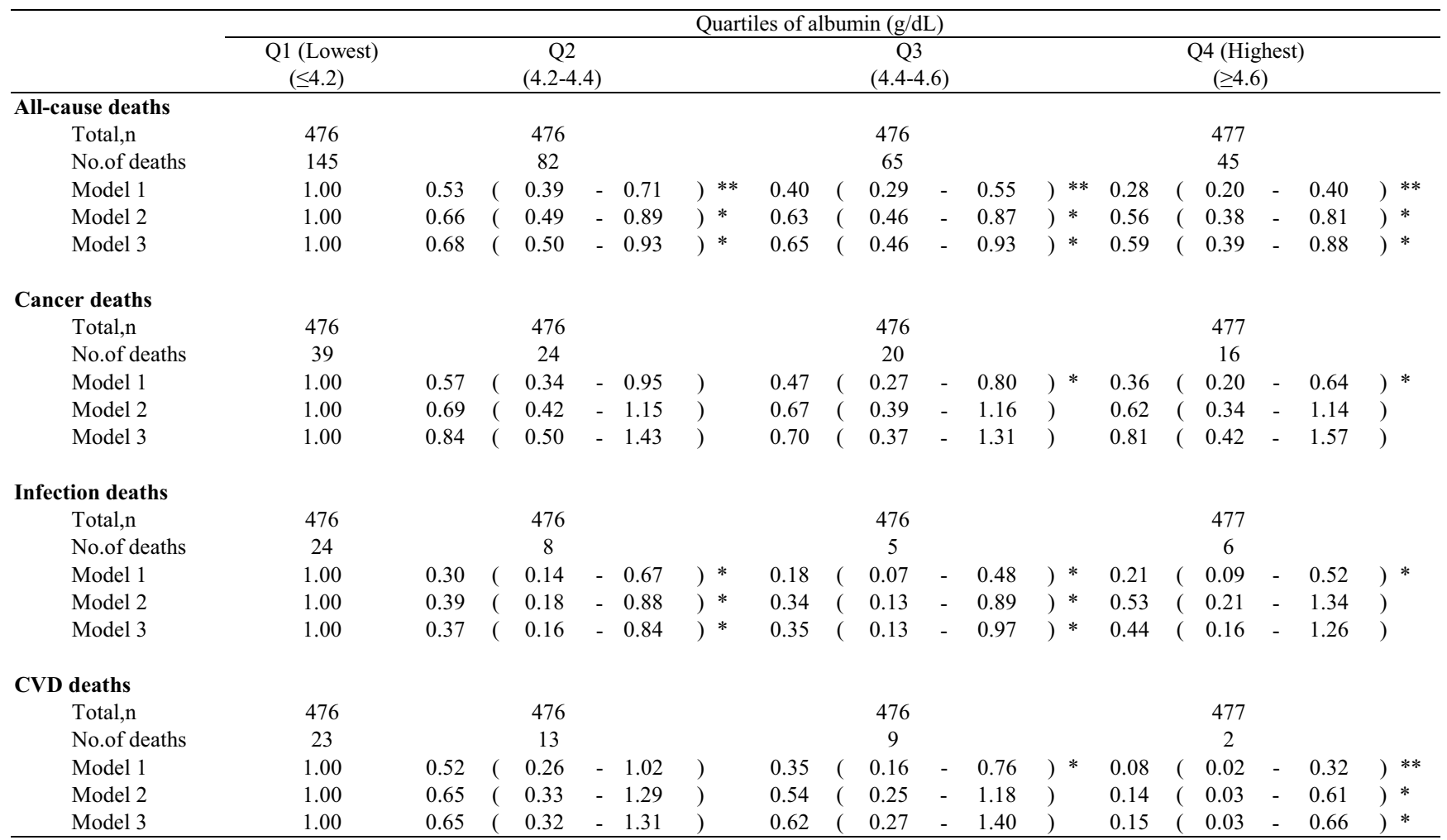

CVD: Cerebro-cardiovascular diseases

Model 1; crude, Model 2; age and sex adjusted, Model 3; adjusted for age, sex, HDL-cholesterol, LDL-cholesterol, triglycerides and estimatied glomerular filter.

$* \mathrm{p}<0.01$ vs. Q1, **p $<0.001$ vs.Q1

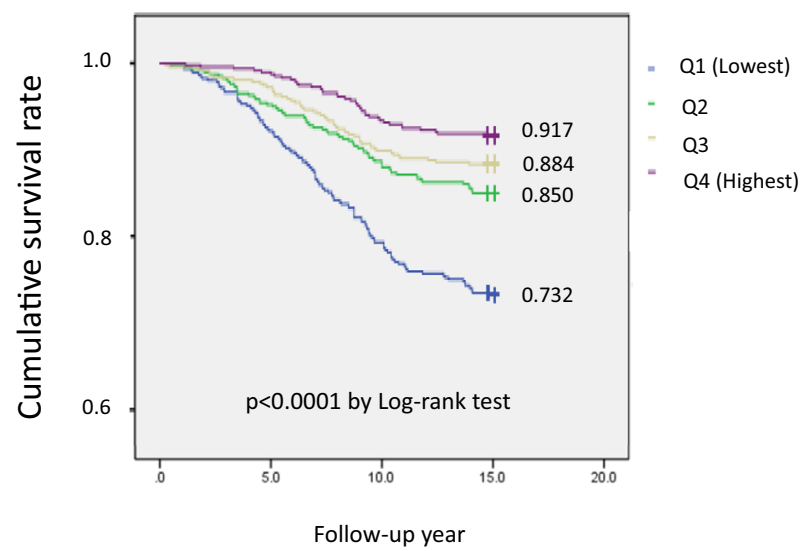

Figure 2. Cumulative survival curves stratified by serum albumin quartiles in subjects estimated by the Kaplan-Meier method. There was a significant trend across the quartiles ( $\mathrm{p}<0.0001$ by log-rank test). Q1: Albumin $\leq 4.2 \mathrm{~g} / \mathrm{dL} \quad(\mathrm{p}=476)$. Q2: Albumin 4.2-4.4g/dL ( $p=476$ ). Q3: Albumin 4.4-4.6g/dL (p=476). Q4: Albumin $\geq 4.6 \mathrm{~g} / \mathrm{dL}(\mathrm{p}=477)$

the present study, the enrolled subjects were free from apparent cerebro-cardiovascular disease at the start of the study period and their serum albumin levels were within the normal range. Furthermore, after adjusting for confounding factors, the Cox proportional hazards regression analysis demonstrated that a low albumin level was an independent predictor of all-cause death and cerebro-cardiovascular disease death (Table 5). In contrast, the subjects with the highest albumin level had the lowest mortality rate, indicating that a small variation within the normal range of the albumin level could have an effect on future all-cause mortality, even in a general population. The precise mechanism underlying the relationship between serum albumin levels and mortality should be clarified in future studies.

Next, we focused on the association between nutrient intake and all-cause/cause-specific death, vegetable protein intake was the only nutrient-related factor that was found to be associated with mortality (Table 4). The previous reports did not consider the nutrient intake of their study populations $(1,2,21-31)$. Our findings suggest that it is likely that the nutrient intake of the healthy subjects in the present study did not directly influence their serum albumin levels. Malabsorption or protein loss might be considered when an imbalance is detected between a subject's albumin level and his or her nutrient intake. This issue should be clarified in future studies.

\section{Study limitations}

The present study is associated with several limitations. First, in order to exclude subjects with cardiovascular diseases, we carefully examined their medical history, and performed physical examinations. The subjects with $\mathrm{Q}$ waves 
on an electrocardiogram were excluded. However, it is possible that some subjects with asymptomatic cardiovascular diseases might have been included. Second, we were not able to exclude subjects with undetected cancer. Third, the total number of deaths from cerebro-cardiovascular disease and cancers was small, which limited the statistical power of the outcome. Fourth, we used a single baseline measurement to predict the all-cause and cause-specific death. Fifth, we did not have data on chronic hepatitis in the present study. Thus, some subjects' serum albumin levels might have been influenced by chronic hepatitis. Finally, the pathophysiological mechanism underlying the association between low albumin levels and all-cause death was not revealed from our observational study.

\section{Conclusion}

In conclusion, the present study demonstrated that the serum albumin level was an independent predictor of all-cause and cerebro-cardiovascular disease death in the Japanese general population.

The authors state that they have no Conflict of Interest (COI).

\section{Acknowledgement}

We are grateful to the members of the Japan Medical Association of Ukiha, the elected officials and residents of Tanushimaru, and the team of physicians who helped in performing the health examinations.

\section{References}

1. Okamura T, Hayakawa T, Hozawa A, et al; NIPPON DATA 80 Research Group. Lower levels of serum albumin and total cholesterol associated with decline in activities of daily living and excess mortality in a 12-year cohort study of elderly Japanese. J Am Geriatr Soc 56: 529-535, 2008.

2. Takata Y, Ansai T, Yoshihara A, Miyazaki H. Serum albumin levels and 10-year mortality in a community-dwelling 70-year-old population. Arch Gerontol Geriatr 54: 39-43, 2012.

3. Herrmann FR, Safran C, Levkoff SE, Minaker KL. Serum albumin level on admission as a predictor of death, length of stay, and readmission. Arch Intern Med 152: 125-130, 1992.

4. Vincent JL, Dubois MJ, Navickis RJ, Wilkes MM. Hypoalbuminemia in acute illness: Is there a rationale for intervention? A metaanalysis of cohort studies and controlled trials. Ann Surg 237: 319-334, 2003.

5. Sullivan DH, Roberson PK, Bopp MM. Hypoalbuminemia 3 months after hospital discharge: significance for long-term survival. J Am Geriatr Soc 53: 1222-1226, 2005.

6. Foley RN, Partrey PS, Harnett JD, Kent GM, Murray DC, Barre PE. Hypoalbuminemia, cardiac morbidity, and mortality in endstage renal disease. J Am Soc Nephrol 7: 728-736, 1996.

7. Cooper BA, Penne EL, Bartlett LH, Pollock CA. Protein malnutrition and hypoalbuminemia as predictors of vascular events and mortality in ESRD. Am J Kidney Dis 43: 61-66, 2004.

8. Menon V, Greene T, Wang X, et al. C-reactive protein and albu$\min$ as predictors of all-cause and cardiovascular mortality in chronic kidney disease. Kidney Int 68: 766-772, 2005.

9. Dziedzic T, Pera J, Slowik A, Gryz-Kurek EA, Szczudlik A. Hypoalbuminemia in acute ischemic stroke patients: frequency and correlates. Eur J Clin Nutri 61: 1318-1322, 2007.

10. Kinugasa $Y$, Kato M, Sugihara S, et al. A simple risk score to predict in hospital death of elderly patients with acute decompensated heart failure: hypoalbuminemia as an additional prognostic factor. Circ J 73: 2276-2281, 2009.

11. Hartopo AB, Gharini PPR, Stetianto BY. Low serum albumin levels and in-hospital adverse outcomes in acute coronary syndrome. Int Heart J 51: 221-226, 2010.

12. Hirai Y, Geleijnse JM, Adachi H, Imaizumi T, Kromhout D. Systolic blood pressure predicts cardiovascular mortality in a farming but not in a fishing community: A 40-year follow-up of the Japanese cohorts of the Seven Countries Study. Circ J 75: 1890-1896, 2011.

13. Hino A, Adachi H, Toyomasu K, et al. Very long chain N-3 fatty acids intake and carotid atherosclerosis: An epidemiological study evaluated by ultrasonography. Atherosclerosis 176: 145-149, 2004.

14. De Bacquer D, De Backer G, Kornitzer M. Prevalence of ECG findings in large population based samples of men and women. Heart 84: 625-633, 2000.

15. Matsuo S, Imai E, Horio M, et al; collaborators developing the Japanese equation for estimated GFR. Revised equations for estimated GFR from serum creatinine in Japan. Am J Kidney Dis 53: 982-992, 2009.

16. Thompson FE, Byers T. Dietary assessment resource manual. J Nutr 124: 2245S-2317S, 1994.

17. The ARIC Investigators. The atherosclerosis risk in communities (ARIC) study: Design and objectives. Am J Epidemiol 129: 687$702,1989$.

18. Standard tables of food composition in Japan. 4th revised ed. Resource council science and technology agency, Printing bureau Ministry of Finance, Japan, 1999 (in Japanese).

19. The National Nutrition Survey, 1999. Ishikawa S, Ed. The Ministry of Welfare and Labor, Japan, Daiichi Publishing Co., Ltd, 2001: 65-70 (in Japanese).

20. World Health Organization. International Statistical Classification of Diseases and Related Health Problems. 10th Revision. WHO, Geneva, 2003.

21. Okumura K, Iseki K, Wakugami K, et al. Low serum cholesterol as a risk factor for hemorrhagic stroke in men. - A communitybased mass screening in Okinawa, Japan-. Jpn Circ J 63: 53-58, 1999.

22. Famakin B, Weiss P, Herzberg V, et al. Hypoalbuminemia predicts acute stroke mortality: Paul Coverdell Georgia stroke registry. J Stroke Cerebrovasc Dis 19: 17-22, 2010.

23. Takeuchi T, Adachi H, Ohuchida M, et al. A case-control study found that low albumin and smoking were associated with aortic dissection. J Clin Epidemiol 57: 386-391, 2004.

24. Corti MC, Guralnik JM, Salive ME, Sorkin JD. Serum albumin level and physical disability as predictors of mortality in older persons. JAMA 272: 1036-1042, 1994.

25. Shah NR, Dumler F. Hypoalbuminaemia - A marker of cardiovascular disease in patients with chronic kidney disease stage II-IV. Int J Med Sci 5: 366-370, 2008.

26. Wiedermann CJ, Wiedermann W, Joannidis M. Hypoalbuminemia and acute kidney injury: a meta-analysis of observational clinical studies. Intensive Care Med 36: 1657-1665, 2010.

27. Crumley ABC, Stuart RC, McKernan M, McMillan DC. Is hypoalbuminemia an independent prognostic factor in patients with gastric cancer? World J Surg 34: 2393-2398, 2010.

28. Filippatos GS, Desai RV, Ahmed MI, et al. Hypoalbuminaemia and incident heart failure in older adults. Eur J Heart Fail 13: 1078-1086, 2011.

29. Bonilla-Palomas JL, Gámez-López AL, Moreno-Conde M, et al. Hypoalbuminemia in acute heart failure patients: Causes and its impact on hospital and long-term mortality. J Cardiac Fail 20: 350-358, 2014. 
30. Gatta A, Verardo V, Bolognesi M. Hypoalbuminemia. Intern Emerg Med 7: S193-S199, 2012.

31. Eustace JA, Astor B, Muntner PM, Ikizler TA, Coresh J. Prevalence of acidosis and inflammation and their association with low serum albumin in chronic kidney disease. Kidney Int 65: 10311040,2004
The Internal Medicine is an Open Access article distributed under the Creative Commons Attribution-NonCommercial-NoDerivatives 4.0 International License. To view the details of this license, please visit (https://creativecommons.org/licenses/ by-nc-nd/4.0/).

(C) 2016 The Japanese Society of Internal Medicine http://www.naika.or.jp/imonline/index.html 